\title{
Complete and Early Vitrectomy for Endophthalmitis After Cataract Surgery: An Alternative Treatment Paradigm [Response To Letter]
}

\author{
Bernard Dib (I) ${ }^{1-4}$ \\ Robert E Morris (iD ${ }^{I-4}$ \\ Matthew H Oltmanns (iD ${ }^{1-4}$ \\ Mathew R Sapp ${ }^{1-4}$ \\ Jay $\mathrm{P}$ Glover ${ }^{5}$ \\ Ferenc Kuhn ${ }^{2,6,7}$ \\ 'Retina Specialists of Alabama, \\ Birmingham, AL, USA; ${ }^{2}$ Helen Keller \\ Foundation for Research and Education, \\ Birmingham, Al, USA; ${ }^{3}$ University of \\ Alabama at Birmingham (UAB), \\ Department of Ophthalmology, \\ Birmingham, Al, USA; ${ }^{4}$ UAB Callahan Eye \\ Hospital, Birmingham, Al, USA; ${ }^{5}$ Retina \\ Consultants of Nashville, Nashville, TN, \\ USA; ${ }^{6}$ Milos Eye Hospital, Belgrade, \\ Serbia; ${ }^{7}$ Zagorskiego Eye Hospital, \\ Krakow, Poland
}

\section{Dear editor}

We are grateful for Dr. Surbhi Agrawal's inquiries regarding retinal detachment, systemic antibiotics, retreatment decisions, examination continuity, and Endophthalmitis Vitrectomy Study (EVS) comparisons. We will try to respond in order and succinctly.

The primary purpose of our retrospective case series treating acute postcataract endophthalmitis (APCE) eyes was to show that using fundus obscuration as the indication for immediate complete vitrectomy ( $77 \%$ of cases) and retreating $(61 \%$ of cases) whenever infection control remained in doubt, resulted in substantially greater salvage of good vision ( $79 \%$ of eyes $20 / 40$ or better) than has heretofore been published in any detailed case series. Initial tap/inject predominates in other series, with results ranging from $25 \%$ to $50 \%$ recovery of $20 / 40$ visual acuity. ${ }^{1}$

\section{Retinal Detachment}

In our experience, endophthalmitis-related retinal detachments usually occur from necrotic holes rather than from iatrogenic tears (see images). The best randomized evidence we will likely ever have to support this theory comes from the EVS itself, which found that the rate of retinal detachment was highly correlated with infection severity, with no difference observed between the VIT and TAP groups. ${ }^{2}$ If this held true in the 20 gauge era, ${ }^{3}$ the iatrogenic contribution of vitrectomy is even less pronounced with high speed, small gauge cutters that have now substantially reduced the risk of producing retinal tears. ${ }^{4}$

Using such technology, we found that more complete vitrectomy and its more frequent use ( $89 \%$ of eyes vs $54 \%$ of EVS eyes) did not increase the rate of retinal detachment $\left(6.4 \%\right.$ of eyes vs $8 \%$ of EVS eyes) ${ }^{1,2}$ All 4 retinal detachments in our series occurred in eyes that underwent vitrectomy for especially severe infections. Two eyes (3.2\%) had keratopathy prohibiting complete vitrectomy, and two eyes (3.2\%) had severe existent endophthalmitis retinopathy at initial vitrectomy. Two of those detachments had defects that seemed consistent with necrosis, and the other 2 had nonspecific defects that could not be reliably attributed to iatrogenic injury or necrosis.

Of the seven eyes $(11 \%)$ that did not require initial or subsequent vitrectomy, none developed a retinal detachment. But these were all eyes with less severe
Correspondence: Robert E Morris Retina Specialists of Alabama, 2208 University Blvd, Ste. I0I, Birmingham, Al, 35233, USA

Email rmorris@retinanetwork.com 
infections, a relatively preserved fundus view, and no endophthalmitis retinopathy. A comparative analysis of the retinal detachment risk of TAP vs VIT is therefore not possible in our nonrandomized study.

\section{Systemic Antibiotics}

We believe that appropriate systemic antibiotics likely achieve inhibitory intraretinal levels, protecting against endophthalmitis retinopathy and consequent necrotic holes. This may explain why retinal detachment occurred twice as frequently $(11.2 \%$ vs $5.3 \%)$ in the EVS patients randomized to receive no systemic antibiotics. ${ }^{2}$ Although potentially contributory, we do not believe that the difference in the systemic antibiotics used in our study vs the EVS was a major contributor to the improved visual outcomes seen in our study, as both systemic regimens covered at least $90 \%$ of cultured bacteria. ${ }^{5}$ The EVS itself concurred, ${ }^{5}$ and further concluded that use of systemic antibiotics made no difference in visual acuity outcomes, pointing out that systemic vancomycin specifically does not produce significant vitreous cavity levels relative to direct intravitreal injection., ${ }^{2,5}$ To achieve protective intraretinal antibiotic levels and to facilitate outpatient therapy, we plan to use orally administered moxifloxacin as part of future treatment. ${ }^{6}$

\section{Retreatment}

We sought to achieve early establishment of a toxin-free vitreous cavity, and to maintain it with retreatment as necessary, using recurrent media opacification as the most important indicator of uncontrolled infection and/or inflammation. Substantial endophthalmitis retinopathy at initial vitrectomy OR an ominous gram stain result made us less tolerant of relapsing media opacity, even on postoperative day one; whereas we were more tolerant of modest recrudescence if no substantial retinopathy was found, AND the gram stain result was "benign." An algorithm for such retreatment decisions is being designed.

Confirmation of the need to retreat inadequately responsive eyes is apparent from the fact that $27.5 \%$ of such recultured eyes in this study and $42 \%$ in the EVS remained culture positive at retreatment. ${ }^{1,2}$ Thus, "one and done" treatment (used in $90 \%$ of EVS eyes) failed to promptly sterilize these eyes.

Vitrectomy retreatment was used to remove substantial recurrent purulence, and tap/inject was used alone when media remained reasonably clear, yet infection control remained in doubt. But retreatment with antibiotic injection alone leaves intravitreal toxins produced by viable infecting bacteria and toxins liberated upon their death - both important agents in producing endophthalmitis retinopathy. ${ }^{7,8}$

The financial/emotional strain of a recurrent vitrectomy is preferable to that of the increased vision loss that we are convinced would otherwise occur in eyes so treated. ${ }^{1,2}$

\section{Examination Continuity}

Assessment and treatment by differing physicians was kept to a minimum, with close communication. One of us (BD) is working to develop cell phone based photographic techniques to provide even more reliable comparisons of ocular media for the twice daily examinations we advocate during the critical first 2 days of treatment.

\section{EVS Comparisons}

By using fundus obscuration rather than presenting visual acuity as the determining criterion for initial treatment of APCE eyes, our vitrectomy-favoring treatment differed strikingly from the initial treatment recommendations of the EVS. ${ }^{2}$ We are currently designing a prospective clinical trial of our concepts. A more direct EVS comparison will then be possible. In the meantime, each physician must decide which aspects of our proposed treatment are most important in achieving the best possible outcome for APCE patients.

Known baseline data available from the EVS were presented alongside our study data in Table 1 . They are similar except that $79 \%$ of our eyes were culture positive vs $69 \%$ in the EVS; and virulent bacteria were initially cultured in $29 \%$ of our eyes vs $22 \%$ of EVS eyes. ${ }^{1,2}$ A possible explanation for this difference is that we included only acute presenting cases within 15 days of cataract surgery, whereas EVS eyes were included out to 63 days from cataract surgery. ${ }^{2}$ We expect that eyes presenting so late would more likely be culture negative or nonvirulent, making our improved results in more acute cases all the more remarkable.

\section{Acknowledgment}

We thank Dr. Surbhi Agrawal for prompting clarification of these issues.

\section{Disclosure}

The authors report no conflicts of interest in this communication, financial or otherwise. 


\section{References}

1. Dib B, Morris RE, Oltmanns MH, Sapp MR, Glover JP, Kuhn F. Complete and early vitrectomy for endophthalmitis after cataract surgery: an alternative treatment paradigm. Clin Ophthalmol. 2020;14:1945. doi:10.2147/OPTH.S253228

2. Endophthalmitis Vitrectomy Study Group. Results of the endophthalmitis vitrectomy study. A randomized trial of immediate vitrectomy and of intravenous antibiotics for the treatment of postoperative bacterial endophthalmitis. Arch Ophthalmol. 1995;113(12):1479-1496. doi:10.1001/archopht.1995.01100120009001

3. Morris R, Witherspoon CD, Kuhn F, Byrne JB. Endophthalmitis. In: FH R, editor. Master Tech Ophthalmic Surgery. Philadelphia: Jaypee Brothers Medical Publishers; 1995:560-572
4. Saleh OA, Al-Dwairi RA, Mohidat $\mathrm{H}$, et al. International multi-center study of iatrogenic retinal tears in pars plana vitrectomy. Int J Ophthalmol. 2019;12(6):996-1000. doi:10.18240/ijo.2019.06.19

5. Barza M, Doft BH, Kelsey SF. The endophthalmitis vitrectomy study-reply. Arch Ophthmol. 1996;114:1026-1027. doi:10.1001/ archopht.1996.01100140233032

6. Hariprasad SM, Shah GK, Mieler WF, et al. Vitreous and aqueous penetration of orally administered moxifloxacin in humans. Arch Ophthalmol. 2006;124(2):178-182. doi:10.1001/archopht.124.2.178

7. Kim IT, Park SK, Lim JH. Inflammatory response in experimental Staphylococcus and Pseudomonas endophthalmitis. Ophthalmologica. 1999;213(5):305-310. doi:10.1159/000027444

8. Forster RK. Experimental postoperative endophthalmitis. Trans Am Ophthalmol Soc. 1992;90:505-559.

Dove Medical Press encourages responsible, free and frank academic debate. The content of the Clinical Ophthalmology 'letters to the editor' section does not necessarily represent the views of Dove Medical Press, its officers, agents, employees, related entities or the Clinical Ophthalmology editors. While all reasonable steps have been taken to confirm the content of each letter, Dove Medical Press accepts no liability in respect of the content of any letter, nor is it responsible for the content and accuracy of any letter to the editor.

Clinical Ophthalmology

Dovepress

\section{Publish your work in this journal}

Clinical Ophthalmology is an international, peer-reviewed journal covering all subspecialties within ophthalmology. Key topics include: Optometry; Visual science; Pharmacology and drug therapy in eye diseases; Basic Sciences; Primary and Secondary eye care; Patient Safety and Quality of Care Improvements. This journal is indexed on PubMed

Submit your manuscript here: https://www.dovepress.com/clinical-ophthalmology-journal
Central and CAS, and is the official journal of The Society of Clinical Ophthalmology (SCO). The manuscript management system is completely online and includes a very quick and fair peer-review system, which is all easy to use. Visit http://www.dovepress.com/ testimonials.php to read real quotes from published authors. 